\title{
Notes on the vocalizations of Japanese Robin (Luscinia akahige)
}

Peter Boesman

In the following we briefly analyze and compare voice of the two races of Japanese Robin (Luscinia akahige). We also try to quantify the extent of any vocal differences using the criteria proposed by Tobias et al. (2010), as a support for taxonomic review. We have made use of sound recordings available on-line from Xeno Canto (XC).

A comparison of song of both races, illustrated with sonograms:

tanensis: Song consists of one or two introductory notes followed by a rapid series of notes, usually at fairly high pace but sometimes also slower.
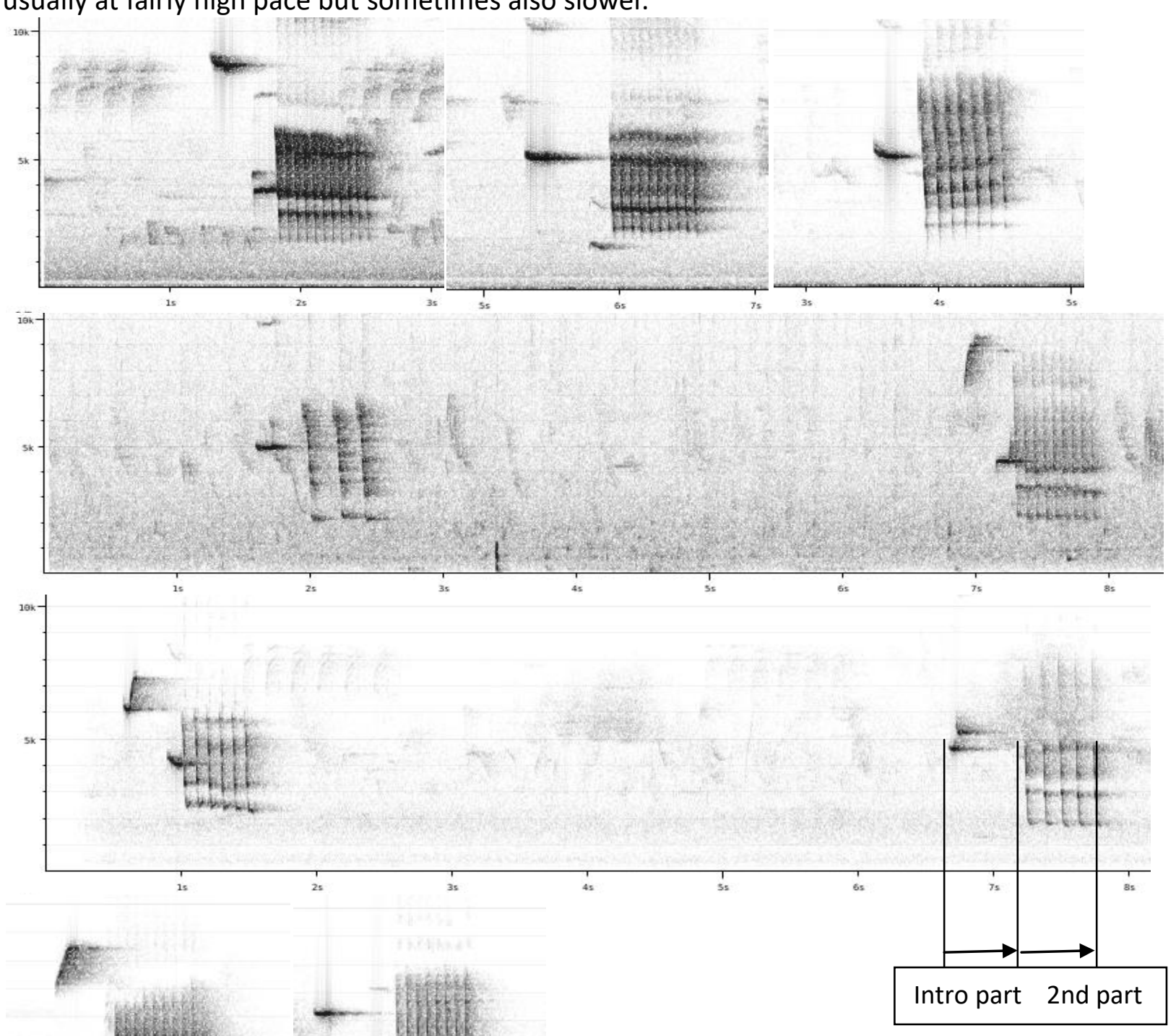


\section{H.

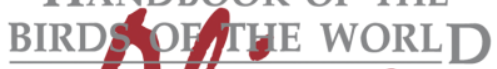 Aluve}

\section{ORNITHOLOGICAL NOTES}

akahige: Song consists of one or two short introductory notes followed by a fairly long highpaced trill, sometimes at slower pace.
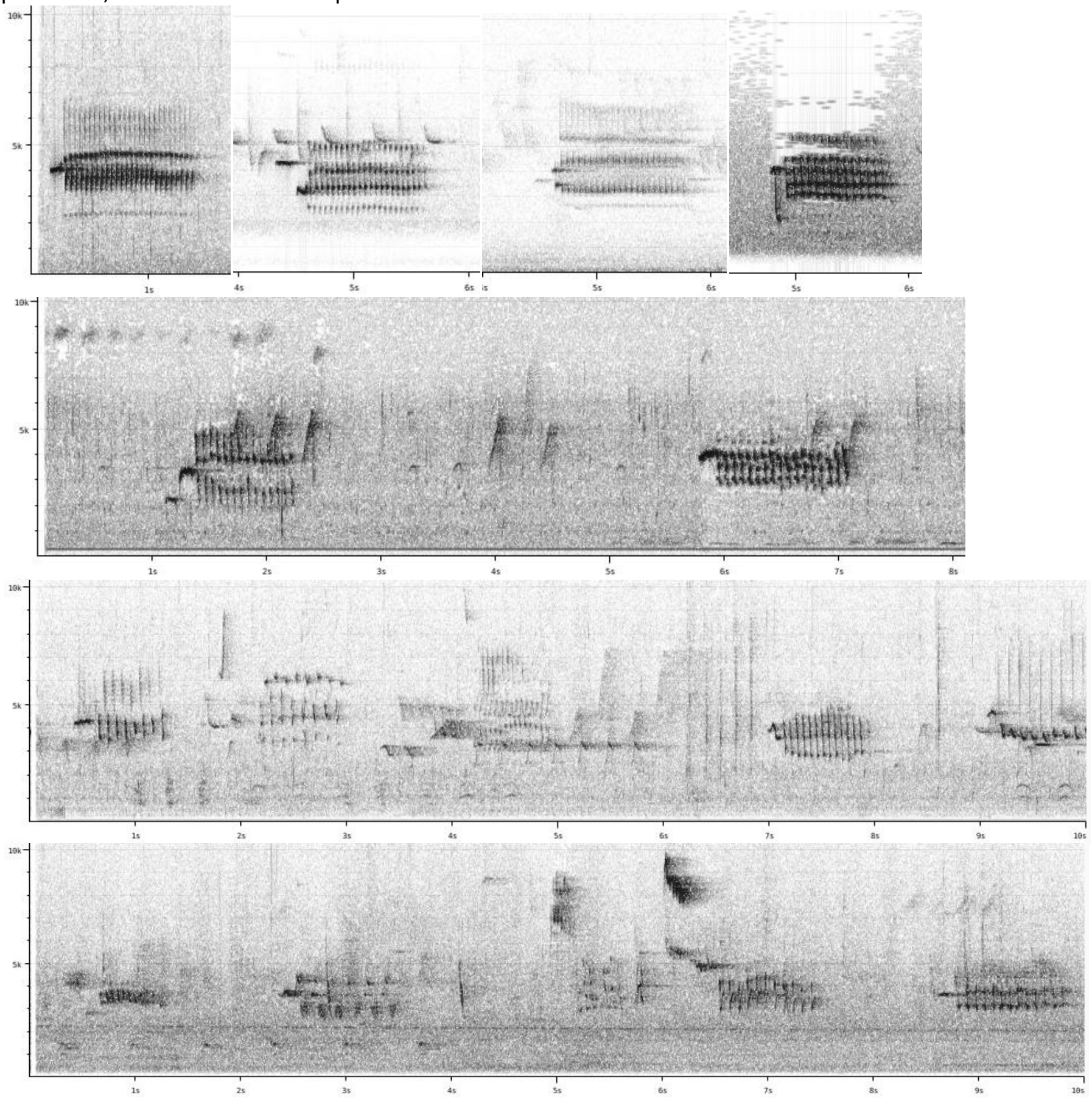

Song of both races is structurally similar, but there are subtle differences as can be seen from the following measurements:

$\begin{array}{lll}\text { duration of introductory part } & \text { c. } 0.3-0.7 \mathrm{~s} & \text { c. } 0.1-0.3 \mathrm{~s} \\ \text { duration of second song part } & \text { c. } 0.6-0.8 \mathrm{~s} & \text { c. } 0.8-1.2 \mathrm{~s} \\ \text { number of notes } & \text { c. } 3-12 & \text { c. } 6-26 \\ \text { max. pace } \mathrm{n} / \mathrm{s} & \text { c. } 5-15 & \text { c. } 6-22 \\ \text { freq. } \text { range second song part } & \text { c. } 4-6 \mathrm{kHz} & \text { c. } 2-5 \mathrm{kHz}\end{array}$



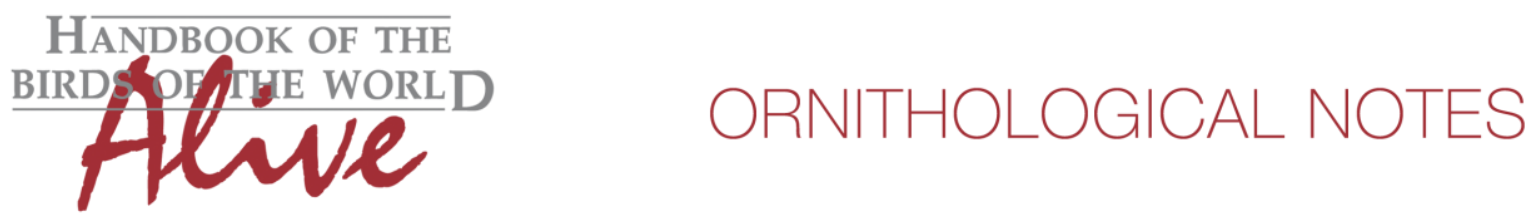

Song of tanensis has longer introductory notes with an overall longer duration of the introductory part (score 1 - 2) and a trilled part of the song which is shorter in duration (score 2) with fewer notes (score 1) delivered at a slightly slower pace and with a slightly larger frequency range (bandwidth).

To the ear, due to pace difference, tanensis sounds more stuttering while akahige more trilled.

When applying Tobias criteria, this would lead to a total vocal score of about 3.

This note was finalized on 16th May 2016, using sound recordings available on-line at that moment. We would like to thank in particular the sound recordists who placed their recordings for this species on XC: Desmond Allen, Lance Benner, Peter Boesman, Frank Lambert, Yann Muzika, Masato Nagai, Anon Torimi and Alex Yakovlev.

\section{References}

Tobias, J.A., Seddon, N., Spottiswoode, C.N., Pilgrim, J.D., Fishpool, L.D.C. \& Collar, N.J. (2010). Quantitative criteria for species delimitation. Ibis 152(4): 724-746.

\section{Recommended citation}

Boesman, P. (2016). Notes on the vocalizations of Japanese Robin (Luscinia akahige). HBW Alive Ornithological Note 324. In: Handbook of the Birds of the World Alive. Lynx Edicions, Barcelona. (retrieved from http://www.hbw.com/node/1252619 on 20 October 2016). 